\title{
A novel electrochemical cell for operando X-ray absorption measurements at low energies: Probing electrochemically induced electronic changes in palladium
}

\author{
Hebe M. Villullas ${ }^{\mathrm{a}, *}$, Felipe B. Ometto ${ }^{\mathrm{a}}$, Gabriel M. Alvarenga ${ }^{\mathrm{a}}$, Flávio C. Vicentin ${ }^{\mathrm{b}}$ \\ a São Paulo State University (UNESP), Institute of Chemistry, Zip Code 14800-060, Araraquara, São Paulo, Brazil \\ ${ }^{\mathrm{b}}$ Brazilian Synchrotron Light Laboratory (LNLS), Brazilian Center for Research in Energy and Materials (CNPEM), Zip Code 13083-970, Campinas, São Paulo, Brazil
}

\section{A R T I C L E I N F O}

\section{Keywords:}

Electrochemical cell

Operando X-ray absorption spectroscopy

Electronic properties

Pd electrocatalyst

\begin{abstract}
A B S T R A C T
Operando assessment of electronic properties near the Fermi level is essential to gain new insights into the mechanisms of electrochemical reactions as well as for the development of more efficient electrocatalysts. However, the high vacuum ambient needed for X-ray absorption measurements at low energies has made studies under electrochemical conditions quite challenging. Here, we describe an out-of-chamber setup with a new electrochemical cell that allowed us to performed operando X-ray absorption studies at the low energy of the Pd L3 edge. Using the new electrochemical cell, we were able to probe, for the first time, the changes in electronic properties of carbon-supported Pd nanoparticles induced by the electrochemical oxidation of the Pd surface. Our results demonstrate that the oxidation process produces an increase in the Pd $4 \mathrm{~d}$ band vacancy, which indicates that charge is transferred from the metal to the adsorbed oxygenated species.
\end{abstract}

\section{Introduction}

Operando spectroscopies have provided unique insights into the structural properties of catalytic materials under working conditions [1]. In particular, X-ray absorption spectroscopy (XAS) has become an important tool in the study of materials for many important electrochemical processes. The distinctive properties of Pt for fuel cell applications have meant that research on materials for low-temperature fuel cells has been focused mainly on carbon-supported Pt and Pt-based electrocatalysts [2]. Fuel cell reactions, such as the reduction of oxygen and the oxidation of hydrogen, methanol and ethanol, involve reaction steps in which adsorption of the reactant molecules and/or reaction intermediates takes place. Because the outermost orbitals are the ones relevant to chemisorption processes, changes in their electronic occupancy, which can be probed by XAS measurements at the L3 edge (involving excitation of $2 p$ electrons to unfilled d orbitals), might have considerable impact on the strength of adsorption, ultimately affecting the catalytic activity and reaction mechanisms. A range of electrochemical cells have been developed for in situ experiments using hard $\mathrm{X}$ rays [3-5]. The high energy of the Pt L3 edge $(11,564 \mathrm{eV})$ has allowed $\mathrm{X}$-ray absorption spectroscopy experiments to be performed under electrochemical conditions for carbon-supported Pt [4,6,7]. The Pt 5d band electronic occupancy can be measured directly at different applied potentials from the near edge region of the absorption spectra (X-ray absorption near edge structure, XANES) [8]. The analysis of spectra beyond the absorption edge (Extended X-ray Absorption Fine Structure, EXAFS) has allowed bond distances and coordination numbers to be assessed, providing valuable results for the characterization of carbonsupported Pt-based alloys [9].

In recent years, rapid progress in the development of membranes for alkaline fuel cells has led to consideration of Pd and Pd-based catalysts as possible alternatives to expensive Pt catalysts [10]. Most X-ray absorption studies of Pd materials have been carried out around the Pd K edge $(24,350.3 \mathrm{eV})$, for which transitions occur only to the final states of p symmetry. In contrast, despite the disadvantages of smaller fluorescence yields than for $\mathrm{K}$ shells, the possibility of more visible multielectron transitions and the fact that for some metals the proximity of $\mathrm{L}$ edges might prevent structural analysis by EXAFS, measurements at the L3 edge (excitation $\mathrm{p} \rightarrow \mathrm{d}$ ), which for transition metals show strong absorption peaks, allow the electronic occupancy of the outermost orbitals to be probed. In this case, direct assessment of the electronic occupancy of the Pd 4d band under electrochemical conditions is constrained by the low Pd L3 edge energy $(3173 \mathrm{eV})$, which lies in the tender X-ray region.

Despite the fact that measurements around the Pd L3 edge are rather scarce for carbon-supported Pd and Pd-based nanoparticles, analysis of

\footnotetext{
* Corresponding author.

E-mail address: mercedes.villullas@unesp.br (H.M. Villullas).
} 
the XANES region of spectra acquired under high-vacuum conditions has shed some light on the role of the electronic occupation of the Pd $4 \mathrm{~d}$ band in electrocatalytic reactions [11,12] and electrochemical surface processes [13].

Although measurements using low-energy X-rays under electrochemical conditions can be quite challenging, a range of experimental setups have been previously reported for operando XAS studies in the soft X-ray region. Different types of electrochemical cells have been designed for use inside a vacuum chamber, such as coin-type cells [14], cells involving liquid flow $[15,16]$, and small tightly sealed cells [17-19]. The main types of electrochemical cells developed for use under vacuum conditions and the results obtained with them have been discussed in review articles [20,21]. With such experimental arrangements, however, changing the samples is not an easy task as this involves the time-consuming processes of venting/pumping the vacuum chamber.

In contrast, conventional electrochemical cells filled with a liquid electrolyte under ambient pressure allow experiments to be performed under conditions that are closer to the real environment of fuel cells and are therefore more suitable for studying materials for fuel cell applications. To the best of our knowledge, operando X-ray absorption studies around the Pd L3 edge under conventional electrochemical conditions have never been reported for supported Pd nanoparticles. Yet, studies of this kind are highly desirable as information on the changes occurring in the electronic properties at different applied potentials and in different electrolytic solutions might offer valuable insights into their roles in electrocatalytic reactions and mechanisms.

In this work, we describe a new electrochemical cell in an out-ofchamber setup that makes it possible to measure X-ray absorption spectra around the Pd L3 edge and to probe, for the first time, the changes in the electronic properties of carbon-supported Pd nanoparticles induced by electrochemical oxidation of the Pd surface.

\section{Materials and methods}

\subsection{Electrochemical cell and out-of-chamber system}

The body of the electrochemical cell was made of PEEK ${ }^{\circledast}$ and the cell cap with openings for reference and auxiliary electrodes was made of Teflon $^{\circledast}$. Fig. 1 shows the main parts of the electrochemical cell. For the working electrode, a window-catalyst assembly was mounted on a removable aluminum holder with a $5 \mathrm{~mm}$ diameter orifice at the center for the X-ray beam to pass through. An Ultralene ${ }^{\circledast}$ film $(4 \mu \mathrm{m})$ was fixed on the removable aluminum holder and a $50 \mathrm{~nm}$ film of titanium was deposited on it by sputtering to enable electrical contact. A layer of

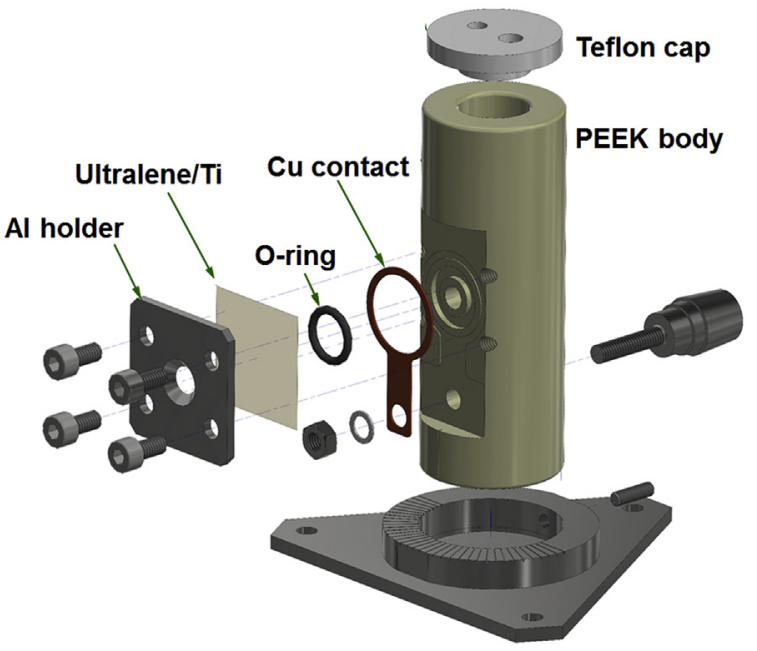

Fig. 1. Main parts of the electrochemical cell.

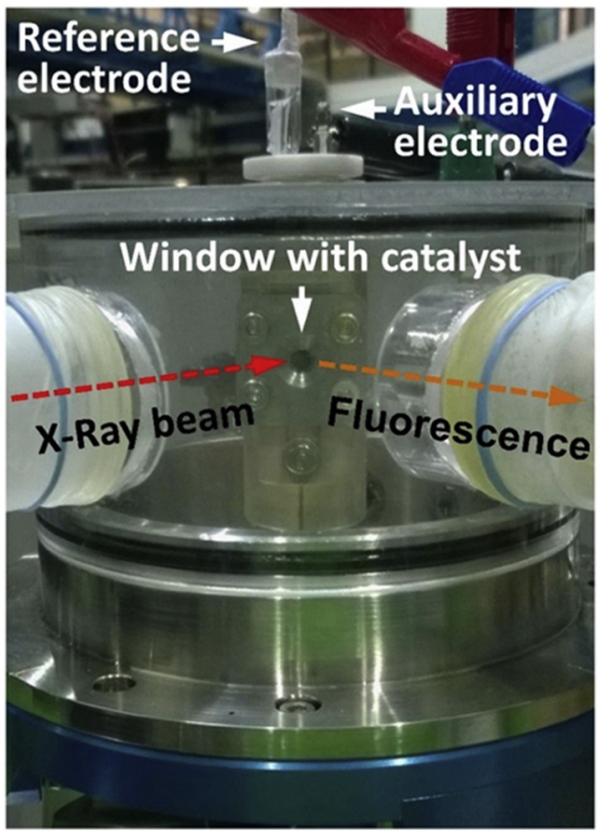

Fig. 2. Out-of-chamber system: electrochemical cell inside the acrylic box used to keep it in a helium atmosphere.

carbon powder (Vulcan XC-72) was deposited onto the titanium film by dropping $10 \mu \mathrm{L}$ of a suspension of carbon powder ( $3 \mathrm{mg}$ of Vulcan XC72 in $0.5 \mathrm{~mL}$ of isopropanol), covering only the region of the central opening. This carbon layer meant that there was no direct contact between the Pd/C catalyst and the Ti film. $10 \mu \mathrm{L}$ of catalyst suspension ( $1.5 \mathrm{mg}$ of catalyst powder in $0.5 \mathrm{~mL}$ of isopropanol) was then deposited on top of the carbon layer and left to dry in air for a few seconds. The aluminum holder was then attached to the cell. An O-ring was used to seal the holder/cell junction and a $\mathrm{Cu}$ ring touching the clean (catalyst-free) Ti film provided the electrical contact for the working electrode.

The electrochemical cell was put in an acrylic box, which was placed outside the vacuum chamber, with lateral entrances for the Xray beam and the detector tip, as shown in Fig. 2. The sample was aligned at an incident angle of $45^{\circ}$ from the incoming beam with the detector placed within the horizontal plane at $90^{\circ}$ from the incoming beam to reduce the elastic scattering background (horizontal polarization from bending magnet). The lateral entrances were joined to the exit of the X-ray beam from the chamber and to the detector with rubber tubing. The measurements were performed with a helium ambient (pressure about 10 mbar above atmospheric pressure) inside the acrylic box in order to minimize the argon fluorescence from air. The upper part of the electrochemical cell, the cell cap and the reference and auxiliary electrodes were all outside the acrylic box.

The catalyst used for this work was a home-made $\mathrm{Pd} / \mathrm{C}$ prepared with $20 \mathrm{wt} \%$ Pd loading. The reference electrode was a reversible hydrogen electrode (RHE); a platinized Pt wire in a separate glass compartment served as the counter electrode. The electrolyte was $0.5 \mathrm{M}$ $\mathrm{H}_{2} \mathrm{SO}_{4}$ solution deoxygenated by $\mathrm{N}_{2}$ bubbling.

\subsection{X-ray absorption measurements}

X-ray absorption spectra were measured at the soft X-ray spectroscopy (SXS) beamline at the Brazilian Synchrotron Light Laboratory (LNLS) [22]. The X-ray beam exited the high vacuum chamber through a beryllium window $7 \mu \mathrm{m}$ thick. The incident photon energy was selected by a $\mathrm{Si}(111)$ double-crystal monochromator with an energy bandwidth of $0.6 \mathrm{eV}$. The photon beam was focused by a Ni-coated toroidal mirror and the spot size at the sample position was 


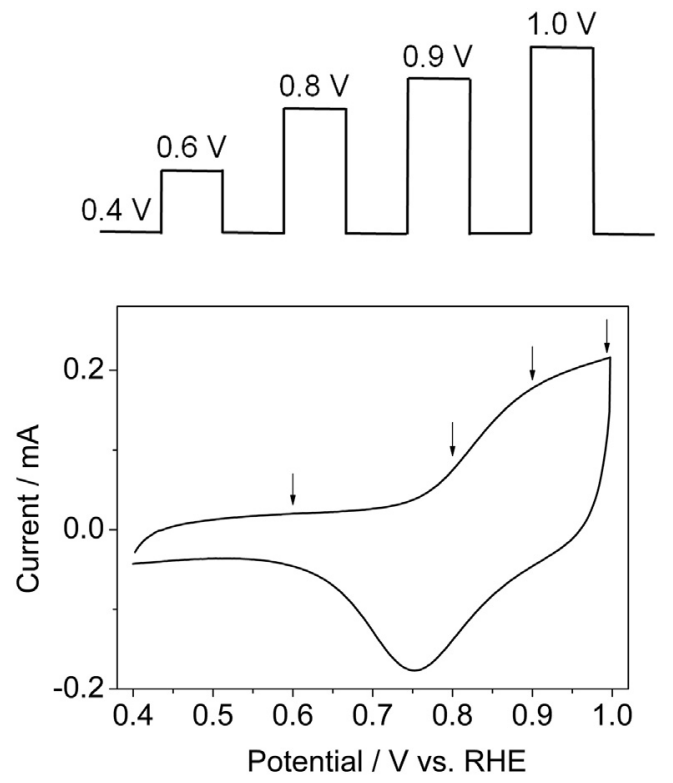

Fig. 3. Potential program followed to collect $\mathrm{X}$-ray absorption spectra for the $\mathrm{Pd} / \mathrm{C}$ catalyst and cyclic voltammetry curve obtained at $50 \mathrm{mV} \mathrm{s}^{-1}$ in deoxygenated $0.5 \mathrm{M} \mathrm{H}_{2} \mathrm{SO}_{4}$ solution.

$0.6 \mathrm{~mm} \times 1.2 \mathrm{~mm}(\mathrm{FWHM})$. X-ray absorption spectra were acquired in partial fluorescence detection mode (SuperFast SDD, AMPTEK) and were normalized by the spectrum simultaneously obtained with a photon flux monitor (Io, aluminum foil) to correct for fluctuations in beam intensity. The collected spectra were normalized with the program Athena from the Demeter software package [23], which was also used to determine the Pd L3 edge energy ( $3173 \mathrm{eV}$ ) of all raw spectra by the zero crossing of the second derivative.

\section{Results and discussion}

The spectra of the $\mathrm{Pd} / \mathrm{C}$ catalyst were acquired in sequence at constant applied potential, after potential steps from $0.4 \mathrm{~V}$ as shown in Fig. 3. The first spectrum was recorded with the sample kept at a potential in the region where the Pd surface is not yet oxidized ( $0.6 \mathrm{~V}$ vs. RHE) and the subsequent spectra were collected with the Pd/C catalyst polarized at $0.8,0.9$ and $1.0 \mathrm{~V}$ vs RHE, i.e., within the region where oxidation of the Pd surface takes place.

A comparison of the normalized X-ray absorption spectra acquired for the Pd/C catalyst at different applied potentials is shown in Fig. 4a. Clearly, the absorption peak intensity moves higher as the applied potential increases. Analysis of the XANES region allows direct assessment of the changes in the electronic occupancy of the Pd $4 \mathrm{~d}$ band induced by the electrochemical oxidation of the Pd surface. The comparative analysis is improved if it is based on the whole absorption peak, not just the maximum intensity. To do this we employed the method proposed by Shukla et al. [8], i.e., fitted the absorption spectrum with a Lorentzian curve combined with an arc tangent curve, with the former representing the transitions to bound states and the latter accounting for transitions to the continuum. The Lorentzian curve is then integrated and the value obtained is proportional to the band vacancy. The results are shown as a function of applied potential in Fig. 4b.

It is interesting to note that similar behavior, i.e., increasing intensity of the X-ray absorption peak for more positive applied potential, has been reported for Pt and Pt-based carbon-supported materials [24-26]. That change in electronic properties was attributed to the effect of oxygenated species leading to a higher electronic vacancy of the $5 \mathrm{~d}$ band [9]. Likewise, the spectra depicted in Fig. 4a show that the electrochemical formation of oxide on the surface of the Pd nanoparticles promotes an increase in the $\mathrm{Pd} 4 \mathrm{~d}$ band vacancy. In other
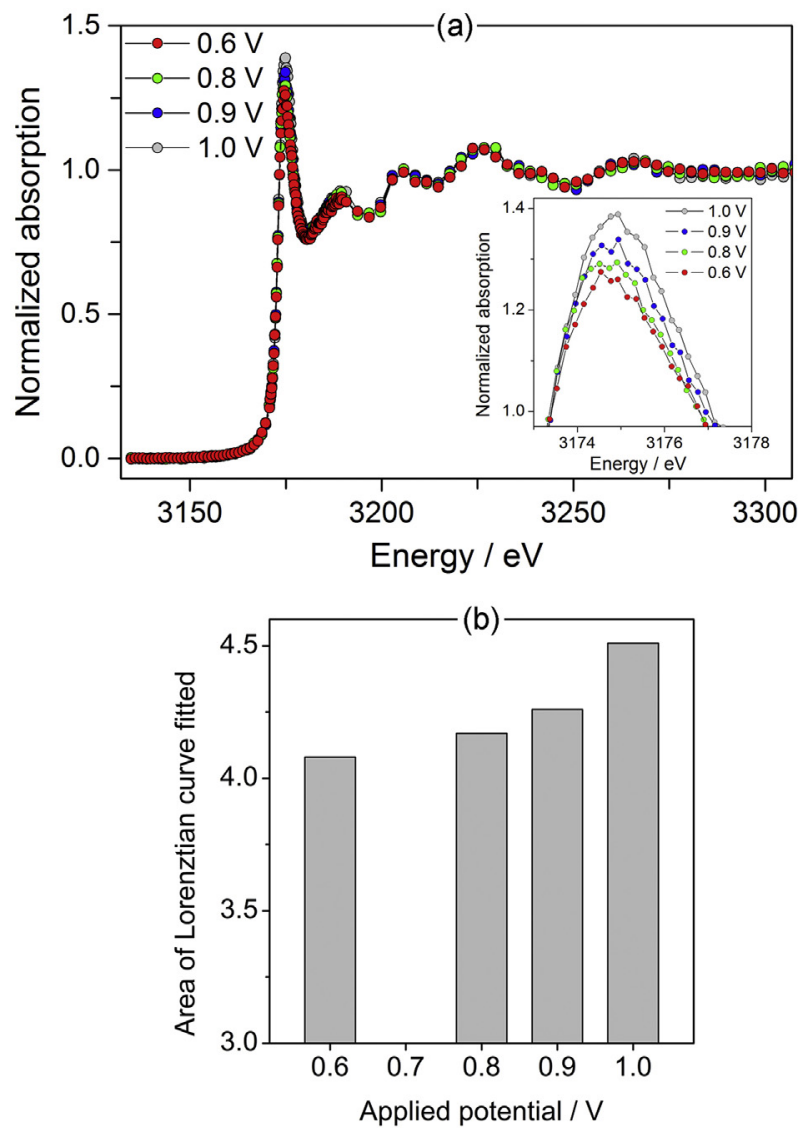

Fig. 4. (a) Comparison of normalized X-ray absorption spectra collected for the $\mathrm{Pd} / \mathrm{C}$ catalyst at different applied potentials in deoxygenated $0.5 \mathrm{M} \mathrm{H}_{2} \mathrm{SO}_{4}$ solution. Inset: Enlarged region of absorption peak. (b) Area of the Lorentzian curve adjusted to the normalized X-ray absorption spectrum as a function of applied potential.

words, when electrochemical oxidation of the Pd surface occurs, there is some charge transfer from the metal to the oxygenated species. To the best of our knowledge, this is the first time that an electrochemically induced change in the electronic vacancy of the Pd $4 \mathrm{~d}$ band has been measured for carbon-supported Pd.

Additionally, the results reported herein demonstrate the feasibility of operando X-ray absorption measurements around the Pd L3 edge and other low absorption edges. The proposed system opens up new possibilities for studying Pd catalysts under ambient pressure and in different electrolyte solutions, deoxygenated with $\mathrm{N}_{2}$ or saturated with other gases. Probing the electronic properties of Pd catalysts under working conditions might provide new insights into fuel-cell-related electrochemical processes, such as adsorption and oxidation of alcohols and $\mathrm{CO}$, because the strength of the interactions of Pd with adsorbates might be profoundly affected by the shifts in the d-band center resulting from alterations in the Pd 4d band electronic occupancy [27]. Moreover, the out-of-chamber system developed might be easily adapted to study the electronic and structural properties of catalysts in other reaction environments, such as small chemical reactors.

\section{Conclusions}

We have developed a new electrochemical cell and a simple out-ofchamber setup that provides an easy way for operando measurements in the soft and tender X-ray region under electrochemical conditions. We probed the changes in the electronic occupancy of the Pd $4 \mathrm{~d}$ band resulting from the application of different potentials and observed, for the first time, that electrochemical oxidation of the Pd surface led to an 
increase in the band vacancy, indicating that charge is transferred from the metal to the adsorbed oxygenated species.

\section{Acknowledgments}

This work was supported by Fundação de Amparo à Pesquisa do Estado de São Paulo (FAPESP) (2014/12255-6), and Conselho Nacional de Desenvolvimento Científico e Tecnológico (CNPq), (407143/20130). FBO thanks CAPES and GMA thanks FAPESP (2016/05041-5) for the scholarships granted.

\section{Conflicts of interest}

The authors declare no competing interests.

\section{References}

[1] A. Chakrabarti, M.E. Ford, D. Gregory, R.R. Hu, C.J. Keturakis, S. Lwin, Y.D. Tang, Z. Yang, M.H. Zhu, M.A. Banares, I.E. Wachs, A decade plus of operando spectroscopy studies, Catal. Today 283 (2017) 27-53, https://doi.org/10.1016/j.cattod. 2016.12.012.

[2] O.T. Holton, J.W. Stevenson, The role of platinum in proton exchange membrane fuel cells: Evaluation of platinum's unique properties for use in both the anode and cathode of a proton exchange membrane fuel cell, Platin. Met. Rev. 57 (2013) 259-271, https://doi.org/10.1595/147106713x671222.

[3] J. McBreen, W.E. Ogrady, K.I. Pandya, R.W. Hoffman, D.E. Sayers, EXAFS study of the nickel-oxide electrode, Langmuir 3 (1987) 428-433, https://doi.org/10.1021/ la00075a027.

[4] M.E. Herron, S.E. Doyle, S. Pizzini, K.J. Roberts, J. Robinson, G. Hards, F.C. Walsh, In situ studies of a dispersed platinum on carbon electrode using X-ray absorption spectroscopy, J. Electroanal. Chem. 324 (1992) 243-258, https://doi.org/10.1016/ 0022-0728(92)80049-a.

[5] N.R.S. Farley, S.J. Gurman, A.R. Hillman, Simple cell for in situ X-ray absorption spectroelectrochemistry, Electr. Commun. 1 (1999) 449-452, https://doi.org/10. 1016/S1388-2481(99)00088-0.

[6] S. Mukerjee, J. McBreen, Effect of particle size on the electrocatalysis by carbonsupported Pt electrocatalysts: an in situ XAS investigation, J. Electroanal. Chem. 448 (1998) 163-171, https://doi.org/10.1016/s0022-0728(97)00018-1.

[7] B.J. Hwang, Y.W. Tsai, J.F. Lee, P. Borthen, H.H. Strehblow, In situ EXAFS investigation of carbon-supported Pt clusters under potential control, J. Synchrotron Radiat. 8 (2001) 484-486, https://doi.org/10.1107/s0909049500019671.

[8] A.K. Shukla, R.K. Raman, N.A. Choudhury, K.R. Priolkar, P.R. Sarode, S. Emura, R. Kumashiro, Carbon-supported Pt-Fe alloy as a methanol-resistant oxygen-reduction catalyst for direct methanol fuel cells, J. Electroanal. Chem. 563 (2004) 181-190, https://doi.org/10.1016/j.jelechem.2003.09.010.

[9] S. Mukerjee, S. Srinivasan, M.P. Soriaga, J. McBreen, Role of structural and electronic properties of Pt and Pt alloys on electrocatalysis of oxygen reduction - an insitu XANES and EXAFS investigation, J. Electrochem. Soc. 142 (1995) 1409-1422, https://doi.org/10.1149/1.2048590.

[10] H. Meng, D.R. Zeng, F.Y. Xie, Recent development of Pd-based electrocatalysts for proton exchange membrane fuel cells, Catalysts 5 (2015) 1221-1274, https://doi. org $/ 10.3390 /$ catal5031221.

[11] G.M. Alvarenga, I.B.C. Gallo, H.M. Villullas, Enhancement of ethanol oxidation on Pd nanoparticles supported on carbon-antimony tin oxide hybrids unveils the relevance of electronic effects, J. Catal. 348 (2017) 1-8, https://doi.org/10.1016/j. jcat.2017.02.002

[12] J. Guo, R. Chen, F.-C. Zhu, S.-G. Sun, H.M. Villullas, New understandings of ethanol oxidation reaction mechanism on $\mathrm{Pd} / \mathrm{C}$ and $\mathrm{Pd}_{2} \mathrm{Ru} / \mathrm{C}$ catalysts in alkaline direct ethanol fuel cells, Appl. Catal. B Environ. 224 (2018) 602-611, https://doi.org/10. 1016/j.apcatb.2017.10.037.

[13] I.B.C. Gallo, E.A. Carbonio, H.M. Villullas, What determines electrochemical surface processes on carbon-supported PdAu nanoparticles? ACS Catal. 8 (2018) 1818-1827, https://doi.org/10.1021/acscatal.7b03734.

[14] L. Zhang, D. Sun, J. Feng, E.J. Cairns, J.H. Guo, Revealing the electrochemical charging mechanism of nanosized Li2S by in situ and operando X-ray absorption spectroscopy, Nano Lett. 17 (2017) 5084-5091, https://doi.org/10.1021/acs. nanolett.7b02381.

[15] P. Jiang, J.L. Chen, F. Borondics, P.A. Glans, M.W. West, C.L. Chang, M. Salmeron, J.H. Guo, In situ soft X-ray absorption spectroscopy investigation of electrochemical corrosion of copper in aqueous $\mathrm{NaHCO}_{3}$ solution, Electr. Commun. 12 (2010) 820-822, https://doi.org/10.1016/j.elecom.2010.03.042.

[16] C. Schwanke, R. Golnak, J. Xiao, K.M. Lange, Electrochemical flowcell for in-situ investigations by soft x-ray absorption and emission spectroscopy, Rev. Sci. Instrum. 85 (2014) 103120, https://doi.org/10.1063/1.4899063.

[17] K.O. Kvashnina, S.M. Butorin, A. Modin, I. Soroka, M. Marcellini, J.H. Guo, L. Werme, J. Nordgren, Changes in electronic structure of copper films in aqueous solutions, J. Phys. Condens. Matter 19 (2007) 226002, https://doi.org/10.1088/ 0953-8984/19/22/226002.

[18] D.K. Bora, P.A. Glans, J. Pepper, Y.S. Liu, C. Du, D.W. Wang, J.H. Guo, An ultra-high vacuum electrochemical flow cell for in situ/operando soft X-ray spectroscopy study, Rev. Sci. Instrum. 85 (2014) 043106, https://doi.org/10.1063/1.4870795.

[19] K. Nakanishi, D. Kato, H. Arai, H. Tanida, T. Mori, Y. Orikasa, Y. Uchimoto, T. Ohta, Z. Ogumi, Novel spectro-electrochemical cell for in situ/operando observation of common composite electrode with liquid electrolyte by X-ray absorption spectroscopy in the tender X-ray region, Rev. Sci. Instrum. 85 (2014) 084103, https://doi. org/10.1063/1.4891036.

[20] E.J. Crumlin, Z. Liu, H. Bluhm, W.L. Yang, J.H. Guo, Z. Hussain, X-ray spectroscopy of energy materials under in situ/operando conditions, J. Electron Spectrosc. Relat Phenom. 200 (2015) 264-273, https://doi.org/10.1016/j.elspec.2015.06.008.

[21] X.S. Liu, W.L. Yang, Z. Liu, Recent progress on synchrotron-based in-situ soft X-ray spectroscopy for energy materials, Adv. Mater. 26 (2014) 7710-7729, https://doi. org/10.1002/adma.201304676.

[22] M. Abbate, F.C. Vicentin, V. Compagnon-Cailhol, M.C. Rocha, H. Tolentino, The soft X-ray spectroscopy beamline at the LNLS: technical description and commissioning results, J. Synchrotron Radiat. 6 (1999) 964-972, https://doi.org/10.1107/ s0909049599008122.

[23] B. Ravel, M. Newville, ATHENA, ARTEMIS, HEPHAESTUS: data analysis for X-ray absorption spectroscopy using IFEFFIT, J. Synchrotron Radiat. 12 (2005) 537-541, https://doi.org/10.1107/S0909049505012719.

[24] E. Antolini, J.R.C. Salgado, M.J. Giz, E.R. Gonzalez, Effects of geometric and elec tronic factors on ORR activity of carbon supported Pt-Co electrocatalysts in PEM fuel cells, Int. J. Hydrog. Energy 30 (2005) 1213-1220, https://doi.org/10.1016/j ijhydene.2005.05.001.

[25] F.H.B. Lima, J.F.R. de Castro, L. Santos, E.A. Ticianelli, Electrocatalysis of oxygen reduction on carbon-supported Pt-Co nanoparticles with low Pt content, J. Power Sources 190 (2009) 293-300, https://doi.org/10.1016/j.jpowsour.2008.12.128.

[26] R. Gentil, H.M. Villullas, Oxygen reduction activity and methanol tolerance of carbon-supported PtV nanoparticles and the effects of heat treatment at low temperatures, J. Solid State Electrochem. 20 (2016) 1119-1129, https://doi.org/10. 1007/s10008-015-2953-1.

[27] F.H.B. Lima, J. Zhang, M.H. Shao, K. Sasaki, M.B. Vukmirovic, E.A. Ticianelli, R.R. Adzic, Catalytic activity-d-band center correlation for the $\mathrm{O}_{2}$ reduction reaction on platinum in alkaline solutions, J. Phys. Chem. C 111 (2007) 404-410, https://doi.org/10.1021/jp065181r. 